\title{
The ecology of urban system: assessment using Spiraea plants
}

\author{
Anna Lugovskaya ${ }^{1 *}$, Elena Khramova ${ }^{2}$, and Evgenia Karpova ${ }^{2}$ \\ ${ }^{1}$ Siberian State University of Geosystems and Technologies, 630108 Novosibirsk, Russia \\ ${ }^{2}$ Central Siberian Botanical Garden SB RAS, 630090 Novosibirsk, Russia
}

\begin{abstract}
The article presents the results of the study of the shift in the morphological parameters of the leaves of three species of the genus Spiraea L. growing under the conditions of transport-caused and industrial pollution in large industrial citi of Western Siberia (Novosibirsk) in comparison with that in background conditions (reference). The morphological indices (length, width, perimeter, and area of the lamina) were determined by digital image analysis using the Maplnfo software. The anthropogenic impacts induced a reduction in the size of the assimilating organs and an increase in the index of the fluctuating asymmetry of the leaves of urban plants compared to background plants. According to the fluctuating asymmetry index, the environmental quality of the Lenin district of Novosibirsk was assessed as critical, meanwhile that of the reference conditions corresponded to the norm.
\end{abstract}

The environmental situation in large industrial cities of Western Siberia, including Novosibirsk, over the past 20-30 years remains tense. Moreover, there is a tendency for its deterioration, mainly due to rising emissions into the atmosphere from constantly growing the number of vehicles, power plants, and other factors [1]. Suspended substances (dust), nitrogen oxides, ammonia, carbon monoxide, formaldehyde, 3,4-benz(a)pyrene are the main pollutants giving excesses of maximum permissible concentration (MPC) in Novosibirsk [2, 3]. In general, the level of atmospheric pollution in the city is evaluated as increased [2].

To keep the health of the population under the conditions of substantial technogenic impact, permanent monitoring of environmental quality is necessary. With an increase in the emission of pollutants into an urban environment, the use of biogeochemical data started to provide an indication of the state of the environment. Objective information on the state of the urban environment allows one to reveal and analyze responses of the biota to technogenic pollution. Many authors use woody plants or their parts as bioindicators for the studies of the urban environment [4-7]. Depending on the species, plants show different resistance to pollution by pollutants, so an important task is to find plants both tolerant to excess pollutants and sensitive to anthropogenic stress to identify the impact of anthropogenic factor on plant objects.

\footnotetext{
${ }^{*}$ Corresponding author: : aulyg@ mail.ru
} 
Species of the genus Spiraea L. are ecologically plastic, gas-tolerant, grow and flower well in urban environments [8]. The bioindicator properties of these plants for the evaluation of environmental pollution were reported in a number of works.

The goal of the work was to determine changes in leaf morphometric parameters of three Spiraea species under the influence of anthropogenic stress and to identify the plant response to pollution to assess environmental quality.

\section{Materials and Methods}

Plants of three species of the genus Spiraea (Rosaceae family) were chosen as objects of study - S. media Fr. Schmidt, S. hypericifolia L.и S. chamaedryfolia L. The plants of Spiraea media, S. hypericifolia, and S. chamaedryfolia growing in the Lenin district of Novosibirsk (the Glory park) under unfavorable environmental conditions (urban conditions) were investigated. According to the data of the West Siberian Department of Meteorology and Environmental Monitoring, the Lenin district is one of the leading sites in the emissions of carbon (II) oxide, sulphur dioxide, nitrogen oxides, and solid pollutants into the atmosphere as a result of technological and other processes. The most substantial contribution to environmental pollution is made by benz(a)pyrene, suspended matter, formaldehyde, ammonia and nitrogen dioxide. The level of atmospheric pollution in the city is considered increased [2]. The plant located next to the park and the roads surrounding it on three sides are sources of dangerous pollution of atmospheric air [3]. Spiraea bushes were planted at a distance of 15-20 m from the road (Plakhotnogo str.) and are separated from the road by a grass lawn, sidewalk, and shrubbery. The reference plants were the bushes of the same age growing in a forest land at the territory of Central Siberian Botanical Garden of the Siberian Branch of the Russian Academy of Science situated in the Sovetskiy district of Novosibirsk (Academy town) with a relatively favorable ecological situation. Plant samples were collected uniformly during the fruiting period in late July 2012 - 2014. From each plant, 10 annual shoots were evenly selected along the perimeter of the crown and from the middle of the shoot was taken leaf for the calculation of morphological indices. The morphological indices (length, width, perimeter and area of the lamina) were determined by digital image analysis using the Maplnfo and MS Excel program packages $[9,10]$.

To evaluate the fluctuating asymmetry (FA) index of the lamina, we used a set of four morphological indices, such as the width of the left and right leaf halves, the length of a second second-order vein, the distance between the bases of the first and second secondorder veins; and the distance between the ends of these veins (Fig. 1).

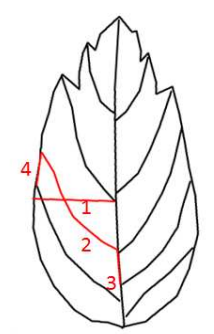

Fig. 1. Scheme of measurement of the morphological indices of the lamina of the plants of the genus Spiraea

The integral FA value for this complex of morphological indices was calculated as the ratio of the doubled modulus of the difference between the left and right (relative to the central vein) parameter values to their sum [11]. To evaluate deviations in the state of an 
organism using the FA index, the score scale proposed for apple leaves by M. Kuznetsov and L. Golyshkin [12] was used. The norm corresponds to FA $<0.100$ (1 point), the transition from the norm to pollution matches $0.100<$ FA $<0.119$ ( 2 points), pollution causes the index to increase to $0.120<\mathrm{FA}<0.139$ ( 3 points), severe pollution induces an even greater increase $0.140<\mathrm{FA}<0.159$ ( 4 points), and FA $>0.159$ ( 5 points) describes pollution as critical. The obtained data were processed by methods of variation statistics using applied MS Excel and the Statistica 10.0 software (Statsoft Inc., Tulsa, OK, USA). Mann-Whitney nonparametric test $(\mathrm{U})$ at significance level $\mathrm{p} \leq 0.05$ was used to determine the significance of the results.

\section{Results and Discussion}

Results of the morphological analysis indicated a decrease in leaf blade surface, length, and width in plants from urban plantings compared to the control, regardless of species and year of observation, in three years under anthropogenic pollution (Table 1).

Table 1. Morphometric indices of Spiraea growing under urban (U) and background (B) conditions in 2012-2014.

\begin{tabular}{|c|c|c|c|c|c|c|}
\hline Plant & 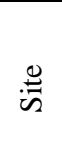 & 㦯 & 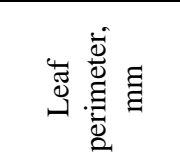 & 焉总 & 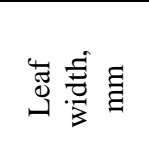 & 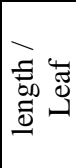 \\
\hline \multicolumn{7}{|c|}{2012} \\
\hline \multirow[t]{2}{*}{ S. media } & $\mathrm{U}^{1}$ & $549 \pm 130^{1}(24)^{2}$ & $107 \pm 36^{*}(34)$ & $39 \pm 12(31)$ & $21 \pm 6^{*}(29)$ & 1,9 \\
\hline & B & $871 \pm 98(11)$ & $119 \pm 21(19)$ & $48 \pm 7(15)$ & $23 \pm 4(17)$ & 2,1 \\
\hline \multirow[t]{2}{*}{ S. hypericifolia } & $\mathrm{U}$ & $100 \pm 83^{*}(83)$ & $59 \pm 31^{*}(53)$ & $28 \pm 4(14)$ & $6 \pm 7(17)$ & 4,6 \\
\hline & B & $166 \pm 33(20)$ & $64 \pm 12$ (19) & $29 \pm 2(7)$ & $9 \pm 1(11)$ & 3,1 \\
\hline \multirow[t]{2}{*}{ S. chamaedryfolia } & $\mathrm{U}$ & $687 \pm 163^{*}(24)$ & $111 \pm 37^{*}(33)$ & $42 \pm 7^{*}(17)$ & $21 \pm 5(24)$ & 2 \\
\hline & B & $1121 \pm 124(11)$ & $173 \pm 16(9)$ & $63 \pm 4(6)$ & $32 \pm 3(9)$ & 2 \\
\hline \multicolumn{7}{|c|}{2013} \\
\hline \multirow[t]{2}{*}{ S. media } & $\mathrm{U}$ & $270 \pm 101^{*}(37)$ & $89 \pm 41^{*}(46)$ & $37 \pm 11$ & $19 \pm 3^{*}(16)$ & 1,9 \\
\hline & B & $628 \pm 37(6)$ & $121 \pm 21(17)$ & $48 \pm 3(6)$ & $23 \pm 2(9)$ & 2,1 \\
\hline \multirow[t]{2}{*}{ S. hypericifolia } & $\mathrm{U}$ & $88 \pm 78^{*}(89)$ & $52 \pm 31^{*}(60)$ & $24 \pm 4(17)$ & $7 \pm 6(86)$ & 3,4 \\
\hline & B & $155 \pm 10(6)$ & $67 \pm 6(9)$ & $30 \pm 1(3)$ & $9 \pm 1(11)$ & 3,3 \\
\hline \multirow[t]{2}{*}{ S. chamaedryfolia } & $\mathrm{U}$ & $691 \pm 78^{*}(11)$ & $105 \pm 31^{*}(30)$ & $44 \pm 4(10)$ & $20 \pm 6(30)$ & 2,2 \\
\hline & B & $1201 \pm 102(8)$ & $163 \pm 26(16)$ & $57 \pm 5(9)$ & $28 \pm 2(7)$ & 2,2 \\
\hline \multicolumn{7}{|c|}{2014} \\
\hline S. media & $\mathrm{U}$ & $300 \pm 124^{*}(41)$ & $102 \pm 38^{*}(37)$ & $41 \pm 17(41)$ & $22 \pm 5$ (29) & 1,9 \\
\hline
\end{tabular}




\begin{tabular}{|l|c|c|c|c|c|c|}
\hline & B & $714 \pm 47(7)$ & $134 \pm 18(13)$ & $53 \pm 7(13)$ & $26 \pm 1(4)$ & 2,0 \\
\hline \multirow{3}{*}{ S. chamaedryfolia } & U & $702 \pm 164^{*}(23)$ & $99 \pm 38^{*}(38)$ & $39 \pm 26^{*}(67)$ & $19 \pm 5(26)$ & 2,1 \\
\cline { 2 - 7 } & B & $1109 \pm 29(3)$ & $180 \pm 21(12)$ & $65 \pm 5(8)$ & $31 \pm 1(3)$ & 2,1 \\
\hline
\end{tabular}

${ }^{1}$ mean value \pm standard deviation; ${ }^{2}-$ coefficient of variation $\left(C_{v}\right)$ in parentheses; $*$ Marked correlations are significant at $\mathrm{p}<0.05$

The value of the leaf length/leaf width ratio in plants of $S$. media from street planting decreased by 1.1 times compared to control plants from the CSBG SB RAS arboretum. In contrast to $S$. media, this ratio in plants of $S$. hypericifolia from outdoor planting was higher (3.4-4.6) in comparison to the control (3.1). The leaf shape of S. chamaedryfolia has no significant changes.

S. hypericifolia in outdoor planting was found to have 1.7-1.8 times less leaf surface area; 1.1-1.3 times less leaf circumference and length; 1.3-1.5 times less leaf width compared to control specimens. Area and perimeter of leaf surface of S. chamaedryfolia from outdoor planting decreased by 1.6-1.8 times; length and width by 1.5-1.7 times compared to control. The lamina area of $S$. media decreased by 1.6-2.4 times, perimeter by 1.1-1.4 times, and length and width of the leaf reduced by 1.1-1.3 times compared to the control specimens.

Significant reduction was revealed only for the leaf area and perimeter (Fig. 2).
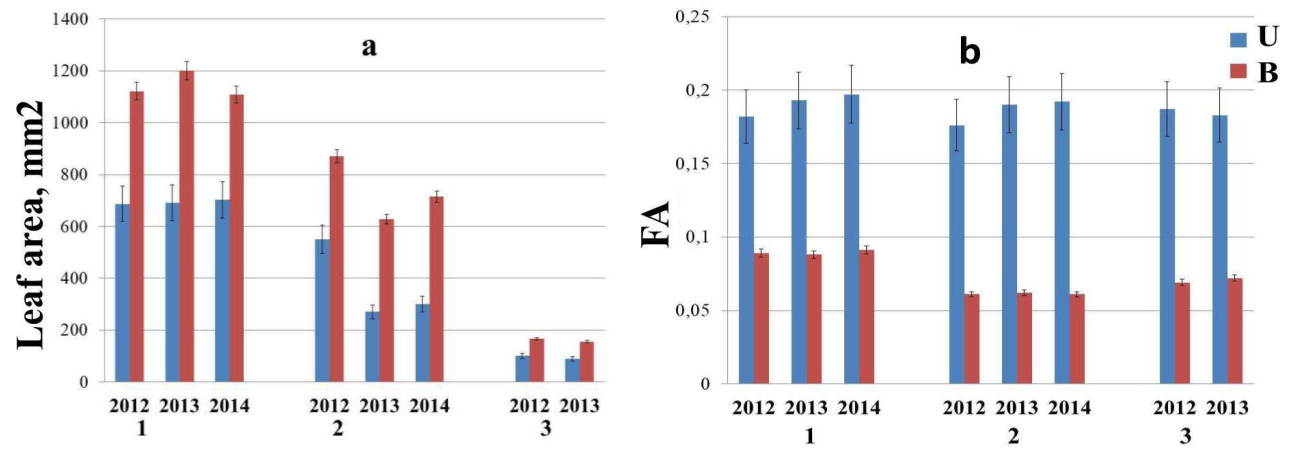

Fig.2. Morphological indices of S. chamaedryfolia (1), S. media (2), and S. hypericifolia (3) from urban (U) and background (B) conditions in 2012-2014: a) leaf area; b) FA index.

The index of fluctuating asymmetry of the lamina of Spiraea plants from outdoor planting (FA $=0.176-0.197)$ was significantly higher than that of plants from the background area $(F A=0.07-0.09)$. According to the FA index, the level of pollution in the sampling sites from urban conditions was estimated as 5 points, and that corresponded to critical pollution. Meanwhile, the control matched 1 point (normal).

\section{Conclusion}

Analysis of the morphological parameters of three Spiraea species growing in urban conditions and the background control showed that the complex of urban factors leads to a decrease in the photosynthetic leaf surface. At the same time, using the fluctuating asymmetry index of $S$. media, $S$. hypericifolia, and $S$. chamaedryfolia, the environmental quality of areas located within the Lenin district of Novosibirsk was assessed as critical, while that of the control site corresponded to the norm. 
The research was carried out in the framework of the state task for the project No. AAAA17-117012610051-5 using the collection of living plants of CSBG SB RAS USU 440534.

\section{References}

1. Ecological infrastructure of a Siberian city: on the example of the Novosibirsk agglomeration (Novosibirsk 2002)

2. The State and Conservation of the Environment in the Novosibirsk Region in 2017 (Novosibirsk, 2018)

3. Yu. Lugovskaya, E. P. Khramova, O. V. Chankina, Contemp. Probl. Ecol., 11 (2018)

4. L. Rikhvanov, D. Yusupov, N. Baranovskaya, A. Yalaltdinova, Ecology and Industry of Russia, 19 (2015)

5. Zh. Tashekova, A. S. Toropov, Bulletin of the Tomsk Polytechnic University. Georesource Engineering, 328(5) (2017)

6. K. S. Patel, R. Sharma, N. S. Dahariya, A. Yadav, B. Blazhev, L. Matini, J. Hoinkis, American Journal of Analytical Chemistry, 8 (2015)

7. N. V. Terekhina, M. D. Ufimtseva, Geography, Environment, Sustainability, 13(1) (2020)

8. A.V. Polozhiy, Flora of Siberia, Vol. 8 (Novosibirsk, Nauka, 1988)

9. Stereo models in the study of biological objects (Novosibirsk, 2006)

10. L. K. Trubina, E. P. Khramova, A. Yu. Lugovskaya, Bulletin of the Siberian State University of Geosystems and Technologies, 4 (2016)

11. Center for Environmental Policy of Russia (Moscow, 2000)

12. M. N. Kuznetsov, L. V. Golyshkin, Agricultural biology, 3 (2008) 